\title{
On the Possibilities and Strategies of Applying Flipped Class Model into College English Class for Chinese Students
}

\author{
Qing Zhao ${ }^{1, \text { a }}$, Ying-jie Guo ${ }^{2, b^{*}}$ \\ ${ }^{1}$ School of Foreign Languages, Xi'an University of Finance and Economics, Xi'an 710100, China; \\ ${ }^{2}$ School of Foreign Languages, Shaanxi Normal University, Xi'an 710062, China. \\ abluehaddylight@163.com, bguoyingjie@snnu.edu.cn
}

Keywords: Possibilities, strategies, Flipped Class Model, Chinese students.

\begin{abstract}
To probe into the possibilities and strategies of applying Flipped Class Model(FCM) into college English class for Chinese students, this thesis initiates the discussion of the background of acquiring a new teaching methodology in Chinese environment. Then, it discusses that both teachers and students may refer to the social awareness of the current teaching situation, the desires of establishing effective classes, and the benefits of FCM itself so as to try FCM reasonably. Next, the thesis relates to the strategies of trying FCM in colleges and universities, which includes establishing a strong belief in educational reform, cultivating advanced high-tech capabilities for both teachers and students, highlighting the essence of humanism in class, etc. One of the striking findings of the thesis is that FCM provides a chance for both Chinese teachers and students to integrate their resources and make their teaching and learning processes the flexible ones. Yet honestly, FCM is not almighty and cannot solve all the teaching problems.
\end{abstract}

\section{Introduction}

At present, English learning has already been an internationalized issue among people. Especially in China, the young and the old, the male and the female, the east and the west, a large circle of people take an enthusiastic attitude towards English and hope that they can communicate with foreigners in English some day in the future. Some are even more ambitious since they would like to travel in western places of interest or study in western universities[1]. Certainly, teaching Chinese students how to listen, speak, read and write English has become an urgent and significant task. To achieve a good result, Chinese governments, institutions, schools and even the kindergartens are trying to think out ways and undertake various responsibilities for different ages of people. The efforts are transparent. As for college English teaching and learning, continuous struggles have never stopped, the objective of which is that both college English teachers and their students can make English a good tool to do good to their respective career and study. However, to harvest an effective teaching and learning atmosphere, a variety of experimental policies have been carried out. It is a pity that these policies are not utterly qualified to make teachers teach rewardingly and let students learn happily. According to the research and study of the scholars at home and abroad[2] , English teaching and learning in Chinese colleges and universities still have a long way to go as many unexpected difficulties come out one after another. The conflicts between traditional teaching methodologies and the fresh ones, among other things, are still sticky to deal with. How to get a successful class has been and will be a long-term goal ahead of both teachers and students.

Flipped Class Model(FCM) is also known as Flipped Classroom or Inverted Classroom. It concernes Maureen Lage, Glenn Platt and Michael Treglia who introduced an unusual teaching methodology in their "Inverting the Classroom: A Gateway to Creating an Inclusive Learning Environment" in 2000; meanwhile, it also relates to J. Wesley Baker who published "The Classroom Flip: Using Web Course Management Tools to Become the Guide by the Side" in the Eleventh International Conference of College Teaching and Learning Communications in the same year. The most known figures regarding FCM belong to Jonathan Bergmann and Aaron Sams who are chemistry teachers in Woodland Park High School of America. They earned reputation because they have practiced the thoughts of FCM in class and intended to popularize the teaching style in the 
teaching procedures of American primary and elementary schools. Nowadays, American colleges and universities also refer to this methodology and try it out[3].

Nonetheless, is FCM possible for Chinese schools, colleges and universities? What lessons can Chinese teachers and students learn from the methodology when acquiring English knowledge? Then what strategies should be considered?

\section{Possibilities of Applying FCM into College English class for Chinese Students}

Social Awareness of the Current Teaching Situation. It is a bit embarrassing to talk about the current teaching situation in some of Chinese colleges and universities, the reason lies in the fact that these colleges and universities still maintain the traditional way of teaching and their teaching style has not changed for years. The curricula are the same, the teachers are the same, the textbooks are the same, yet the society has already moved into another new era. Though undergraduates are produced every year, they feel uncapable enough to take the jobs in various social organizations. Virtually, the students are isolated in the so-called Ivory Tower and appear alienated in front of the social demands. As for college English teaching, unsatisfactory situation exists as well. The problems can be illustrated as follows-Firstly, some English teachers would like to use the same teaching mode for years though students have changed greatly. An interesting phenomenon is that the more excellent an English teacher is, the more unwillingly he/she wants to make a change. Hence, they sustain the teacher-oriented pattern and conduct a one-way output for students; secondly, students receive passive learning in class and they have no abundant opportunities to demonstrate what they want to express in English. Due to this, students act as learning machines as if they were soulless, thoughtless or bull-headed. The teachers dominate the classes all the time, which makes the teaching course boring and unproductive; thirdly, the atmosphere in class seems tedious and unlovely. Because of the unbalanced roles, teachers and students are said to be "teaching" and "being taught" or "governing" and "being governed". The relationship between them turns out to be unequal and tense, which leads to a bad situation--Teachers are so tired while the students take it for granted. What's worse, students would like to play truant and learn what they hope to learn out of class...Briefly, all the social awareness above makes it possible for FCM to do something different for Chinese teachers and students.

Desires of Chinese College English Teachers and Students. Both teachers and students have noticed the poor situation of learning English in class. This can be a good start. Fundamentally speaking, when teachers realize the problems in their teaching and when they are willing to accept the unpleasant realities, they may become the potential forces to revolutionize what they are doing all along. Definitely, teachers' attitudes towards the teaching procedure will do much good to the attitudes of students in learning English knowledge. As a saying goes, there are no bad students; there are only bad teachers. The truth is that teachers will have enormous influence upon students and the efficiency of students' learning. Of course, it is not enough when teachers have desires to make changes in class. Until students are working hard for their mutual destinations can they really enjoy what their teachers are lecturing and what they are learning. As we all know, teaching and learning are basically two systematic courses but they are indispensable and interactive in nature. When teachers have strong desires to teach artfully and devotedly, students can in turn harvest unexpected surprises; meanwhile, when students have strong desires to learn purposely and hopefully, teachers can in turn obtain the due happiness. Certainly, the two sides will get the rewarding experiences rather than the hated ones. In this case, applying FCM into college English class for Chinese students proves not only capable but also reasonable[4].

Various Benefits of Fulfilling FCM. FCM has a number of benefits. Initially, FCM aims to re-organize and re-distribute the time for both teachers and students in and out of class. Frankly, teachers cannot dominate the class all the time any longer, so to speak, students become the real centers. In this particular relationship, the priority of study has been shifted from the sides of teachers to those of students. Additionally, computers are playing more and more important roles in the teaching procedure. As for teachers, computers and videos are very useful means to communicate with students via BBLearn or other high-tech Platforms. Textbooks and lectures are not simply the 
vehicles to pass down knowledge as the teaching ways are believed colorful and varied. Next, FCM makes students become the real owners of their fate. Students can take advantage of the classes and refer to significant resources on line within hours or just minutes. In this teaching mode, teachers' responsibilities do not only depend on "material knowledge transmission"[1,3], instead, the responsibilities rely heavily upon students' critical thinking and responses. The class is not the place to give knowledge, but a place to solve students' inquiries and problems.

\section{Strategies of Applying FCM into College English class for Chinese Students}

Establishing a Strong Belief in Educational Reform. Once we know the possibilities and significance of FCM, both college English teachers and students ought to establish a strong belief in what they try, which surely results in certain educational reform. It is universally acknowledged that English teaching has been a valuable issue to practice, either in colleges or in universities. To some extent, the level and fluency of mastering English can influence students' psychological growth, and students' psychological growth can afterwards affect their teachers to make revolutions in teaching designs, planning, principles, objectives, etc. As a result, the corresponding teaching contents, strategies and destinations will also have to meet challenges. Basically speaking, educational reform, taking FCM as an instance, may encounter some unexpected difficulties. But the most difficult job is not finding the so-called "difficulties", but the confidence and belief to cope with all forms of barriers. Especially for college English, a demanded and comprehensive course, both teachers and students have to integrate many factors into their consideration to enhance the solidity of their horizons and insights. In short, to apply FCM into college English class, establishing a strong belief in educational reform cannot be avoided and ignored.

Cultivating Advanced High-tech Capabilities for Both Teachers and Students. In terms of the ways and notions of applying FCM into college English class, another important factor to guarantee the final effects of learning is that advanced high-tech capabilities should be cultivated and paid attention to on the side of teachers as well as that of students. The reasons are diverse. To begin with, the world we are confronted with nowadays is totally different from that our forebears ever lived in. If our forebears could spend a month or two in sending a letter to their good friends or relatives, we cannot bear the dull and exhausting course just for a message. The point is simple. We have emails and computers. Actually, computers have greatly changed the way of our living and teaching. Particularly in colleges and universities, it is hard to imagine if we have never consulted computers and know nothing about PPT, recording or electric devices. FCM requires teachers and students to get access to high-techs, which concerns teachers' skills of making teaching videos and students' capabilities of employing them.

Highlighting the Essence of Humanism in Class. Merely cultivating high-tech capabilities among college English teachers and students is definitely far from our satisfaction because we also have to highlight the essence of humanism in class. On the one hand, the existence of colleges and universities is for the sake of "molding pure souls and hearts"[5]. To put it specifically, the whole society does not want to witness the brutality and barbarism spreading all over and people within the society do not wish to hold them as their future. On the contrary, the society desires to have "real human beings" and "humane talents" to do favor to their communities and neighborhood. This philosophical belief makes FCM a medium to introduce both teachers and students into the true career of human education, spiritually and physically. On the other hand, the existence of colleges and universities is for the sake of "embracing a bright and promising future". The truth is obvious. The more harmonious a teaching atmosphere is, the more rewarding a learning course will be. Once FCM extends its full wings can both teachers and students create the real flexible environment and reach their successful goals. As we all know, the essence of education lies in inviting the real humanism and "complete humaneness" [4,5]. 


\section{Findings and Discussions}

FCM is a window to view one side of the soundness of educational reform and revolution. Teachers can relieve themselves from heavy, boring and unwarranted tasks while students can free themselves in the world they cherish and enjoy. Most important of all, FCM provides a wonderful chance for both teachers and students to integrate their teaching and learning resources and make their teaching and learning processes the flexible ones. Teachers' styles are renewed and students' autonomous leaning spirits are trained. In this case, the relationship between teachers and students becomes harmonious and good.

However, we also have to confess that in some areas of China, FCM is still a new thing and it does not mean that all Chinese colleges and universities are suitable to practice the ideas and strategies of FCM. China has its particularity and Chinese colleges and universities have their uniqueness. Even though FCM is a good lesson to learn yet it has the special requirements and demanding qualities for both teachers and students. Besides, it is a fact that some teachers, especially aged teachers in China, are not so skillful in using computers and the related high-techs, which turns out to be an unpleasant factor to influence the results of undertaking FCM in class if FCM has been accepted as a universal model.

\section{Summary}

To summarize, FCM is a new model to probe into and practice. In the modern society of China, FCM has caused a variety of changes, either in teaching notions or in the real fulfillment. In the efforts of improving the quality of English learning in colleges and universities, Chinese governments, institutions and the related social organization should sit down and work together to have a reasonable discussion about the effective teaching class model. Of course, the determination should not be subjective and ideal. Instead, it should be flexible and negotiated. FCM provides a new perspective and it is possible for Chinese teachers and students to experiment and examine in their teaching and learning career. Yet generally, Chinese colleges and universities should design good policies and conduct corresponding strategies to meet the increasing social demands and the day-after-day challenges. Last but not least, we also should bear in mind that FCM is not almighty and we cannot depend upon the teaching methodology to solve all the teaching problems in our life.

\section{Acknowledgment}

This research was financially supported by Shaanxi Social Science Fund(2014J11) and 2016 Shaanxi Normal University Research Fund of "Teachers' Teaching Innovation and Practice" (JSJX2016Y007).

\section{References}

[1] L. Huang, China's college English teaching from 1983 to 2012, Foreign Language World. 6 (2014) 57-65.

[2] J. Xie, On college English teaching new models in the big data, Tribune of Education Culture. 2 (2016) 87-91.

[3] Y. H. Cui, Y. Wang, Flipped Class Model and its application to college English teaching, China Educational Technology. 11 (2014) 116-121.

[4] J. N. Li, Z. J. Wu, Practice and reflections on flipped college English class, Foreign Languages in China. 6 (2015) 4-9.

[5] H. M. Liu, Y. F. Chang, A study on the value of university spirit, Educational Research. 8 (2008) 50-55. 